Published in final edited form as:

J Card Fail. 2017 November ; 23(11): 821-825. doi:10.1016/j.cardfail.2017.08.451.

\title{
End-of-Life Discussions in Patients with Heart Failure
}

\author{
Kathleen A. Young, MD*, Margaret M. Redfield, MD ${ }^{\dagger}$, Jacob J. Strand, MD*, and Shannon M. \\ Dunlay, MD, MS ${ }^{\dagger} \pm$ \\ *Department of Medicine, Mayo Clinic, Rochester, MN \\ †Department of Cardiovascular Diseases, Mayo Clinic, Rochester, MN \\ ${ }^{ \pm}$Department of Health Sciences Research, Mayo Clinic, Rochester, MN
}

\begin{abstract}
Background-Although guidelines call on clinicians to conduct regular conversations about advance care planning and end-of-life (EOL) preferences with patients with heart failure (HF), research suggests that physicians often avoid these discussions.
\end{abstract}

Methods and Results-Between January 20, 2014 and January 18, 2016, Southeastern Minnesota residents hospitalized with acute decompensated HF (ADHF) at Mayo Clinic hospitals were enrolled into an observational cohort study that included the administration of face-to-face questionnaires. Risk of death (prognosis) was estimated using the Meta-analysis Global Group in Chronic Heart Failure score. Among 400 patients (mean age 77.7 years, $46 \%$ female, $48 \%$ preserved ejection fraction), only $69(17 \%)$ reported previously discussing EOL wishes with their physician. Patients reporting prior EOL discussions more often had an advance directive ( $81 \%$ vs. $66 \%, \mathrm{p}=0.009$ ), recognized the term 'hospice' ( $96 \%$ vs. $87 \%, \mathrm{p}=0.027$ ), and had more favorable attitudes of dying and hospice $(\mathrm{p}=0.030)$. Resuscitation preferences and rates of completion of advance directives varied with prognosis, though patient-clinician EOL discussions did not.

Conclusions-The majority of patients hospitalized with ADHF did not recall discussing their preferences for EOL care with their physician. This represents an important modifiable gap in the optimal longitudinal care of HF patients.

\section{Keywords}

heart failure; end-of-life; advance care planning; prognosis

Corresponding Author and Request for Reprints: Shannon M. Dunlay MD MS, Mayo Clinic, 200 First Street SW, Rochester, MN 55905; Telephone: (507) 284-8087; Fax: (507)266-7929; dunlay.shannon@ mayo.edu.

DISCLOSURES: The authors have no disclosures.

Publisher's Disclaimer: This is a PDF file of an unedited manuscript that has been accepted for publication. As a service to our customers we are providing this early version of the manuscript. The manuscript will undergo copyediting, typesetting, and review of the resulting proof before it is published in its final citable form. Please note that during the production process errors may be discovered which could affect the content, and all legal disclaimers that apply to the journal pertain. 


\section{INTRODUCTION}

While advances in HF treatment have improved survival after diagnosis, HF still has a high associated mortality and half of individuals will die within five years of diagnosis.(1) However, the clinical trajectory preceding death can vary from patient to patient and is often unpredictable. As such, the importance of considering preferences for future care in advance of an acute event has been well-recognized. National HF guidelines recommend that clinicians engage patients and their family/caregivers in discussions about prognosis and wishes for end-of-life (EOL) care. $(2,3)$ Furthermore, it is recommended that all individuals should document their wishes in the form of an advance directive (AD). To encourage clinicians to make time for these discussions, in 2016, the Center for Medicare and Medicaid Services began financially reimbursing clinicians for participating in advance care planning discussions (ACP) with their patients.

However, research has suggested that most patients with HF are not participating in ACP. One study of patients hospitalized with HF found that more than $80 \%$ did not have an AD. (4) Another study reported that only $41 \%$ of community patients with HF had an AD.(5) This may reflect that clinicians are not routinely initiating ACP discussions with their patients or reviewing their wishes for EOL care, as up to $30 \%$ of clinicians feel ill-equipped to broach these issues.(6) However, whether patients with HF report discussing their wishes for EOL care with their clinicians remains to be determined, as does the potential associations of these discussions with other aspects of ACP, including completion of ADs.

To address these gaps in knowledge, we aimed to determine if patients hospitalized with acute decompensated HF (ADHF) reported ever discussing their wishes for EOL care with their physicians and to assess the patient-level predictors of those discussions. Second, we examined whether EOL preferences differed by prognosis, as assessed using the validated Meta-analysis Global Group in Chronic Heart Failure (MAGGIC) risk score.(7)

\section{MATERIALS AND METHODS}

\section{Study Design and Patient Population}

Between January 20, 2014 and January 18, 2016, Southeastern Minnesota residents hospitalized with ADHF at Mayo Clinic hospitals in Rochester, Minnesota were prospectively recruited into an observational cohort study that included the administration of face-to-face questionnaires. Patients were included in the study if they had chronic HF, were hospitalized with ADHF meeting Framingham criteria, were at least 20 years old, and were residents of one of seven Southeastern Minnesota counties. Questionnaires were administered by a study coordinator. Patients were excluded if they were incapable of completing the questionnaires due to mental or physical limitations. All participants provided written authorization, and the study was approved by the Mayo Clinic Institutional Review Board.

\section{Patient Characteristics}

To determine whether patients had previously discussed their wishes for EOL care with their physicians, patients were asked, "Have you and your doctor discussed any particular wishes 
you have about the care you would want to receive if you were dying?" $(8,9)$ Topics discussed with their physicians, resuscitation preference, completion of $\mathrm{AD}$, attitudes regarding dying and hospice, familiarity with terms 'palliative care' and 'hospice', patient activation, health literacy, health status, marital status, and education were assessed by questionnaire.(8-15) Further details on the survey items are included in the Supplementary Methods.

Demographics, comorbidities, and prescribed medications were collected from the electronic medical record. The date of death was determined using death certificates filed in local counties, obituary notices, and electronic files of death certificates obtained from the State of Minnesota Department of Vital and Health Statistics. The Meta-analysis Global Group in Chronic Heart Failure (MAGGIC) risk score and associated 1-year mortality estimates were calculated using patient characteristics at the time of hospital admission $(7,16)$.

\section{Statistical Analysis}

Missing data were minimal; most variables were complete and all had $<1 \%$ missing. Differences in baseline characteristics in patients who did and did not report discussing their wishes for EOL care with a physician were examined using chi-square, t-tests and Wilcoxon rank-sum tests where appropriate. Differences in EOL preferences and planning in those who did and did not report prior discussions of their wishes for EOL care with their physician were examined using Fisher's exact, chi-square and t-tests. Differences in EOL preferences and planning by prognosis (MAGGIC risk score as continuous variable) were examined using two sample t-tests. All analyses were performed using Stata Version 13 (College Station, TX). A $\mathrm{p}<0.05$ was used as the level of significance.

\section{RESULTS}

A total of 498 patients were approached for inclusion in the study and 400 (80.3\%) agreed to participate. Participant baseline characteristics are shown in Table 1. Non-participants were similar in age (mean age 75.8 vs. 77.7 years, respectively, $\mathrm{p}=0.22)$ and sex (49\% vs. $46 \%$ females, $\mathrm{p}=0.56)$ to participants. The median $\left(25^{\text {th }}-75\right.$ th percentile $)$ time from hospital admission to completion of questionnaires was 2 (1-3) days.

Among 400 patients, only 69 (17\%) reported previously discussing their wishes for EOL care with their physician, 330 patients reported they had not previously discussed their wishes for EOL care with their physician, and one patient had no response. Patients that had previously discussed their wishes for EOL care were more often married (68\% vs 52\%, $\mathrm{p}=0.011$ ), anemic ( $84 \%$ vs $69 \%, \mathrm{p}=0.010$ ) and hyponatremic ( $30 \%$ vs $13 \%, \mathrm{p}=0.002$ ). Patients that reported previously discussing their wishes for EOL care with their physician more often reported that their physician talked about details if they got sicker (36\% vs. 17\%, $\mathrm{p}<0.001)$, how long they had left to live ( $17 \%$ vs. $6 \%, \mathrm{p}=0.001)$, what dying might be like ( $13 \%$ vs. $3 \%, \mathrm{p}=0.002)$, important things in life ( $39 \%$ vs. $21 \%, \mathrm{p}=0.001)$, and spiritual and religious beliefs ( $25 \%$ vs. $7 \%$, p $<0.001$, Supplementary Table).

Patient preferences for prognostic information, resuscitation, prevalence of $\mathrm{AD}$, recognition of the terms 'palliative care' and 'hospice', and attitudes about dying and hospice are shown in Table 2. Patients reporting prior EOL discussions more often had an AD, recognized the term 'hospice', and had more favorable attitudes of dying and hospice. 
The observed 6-month and 1-year mortalities in this study were $26.5 \%$ and $36.5 \%$, respectively. Of the 400 participants, predicted 1-year mortality by MAGGIC risk score ranged from $3.9-72.5 \%$ (median $22.7 \%$ ). A step-wise increase in mortality with higher MAGGIC risk scores was observed (Supplementary Figure), though observed mortality appeared higher than mean predicted mortality across all quartiles. As such, MAGGIC scores were used to qualitatively stratify patients by prognosis. Patients with higher predicted mortality (worse prognosis) more often preferred no resuscitation $(\mathrm{p}=0.002)$ and had an $\mathrm{AD}(\mathrm{p}<0.001$, Figure).

\section{DISCUSSION}

Only $17 \%$ of this cohort of community patients hospitalized with ADHF reported previously discussing their preferences for EOL care with their physician. Patients reporting EOL discussions were more knowledgeable about EOL options and more likely to have completed an AD. Resuscitation preferences and rates of completion of ADs varied with prognosis, though patient-clinician EOL discussions and awareness and attitudes about EOL options did not.

Despite guidelines advocating for ACP discussions in patients with $\operatorname{HF}(2,3,17)$, only a small fraction of patients hospitalized with ADHF reported previously discussing their wishes for EOL care with their doctor. While this may reflect that physicians are not routinely having these discussions with patients, patients also may not recall discussions even if they occurred. Regardless, these data suggest there is room for improvement in the frequency and quality of patient-clinician EOL discussions.

We were surprised to find that there were very few systematic differences between patients who did and did not report discussing their wishes for EOL care with their physicians. While we anticipated that patients who reported prior EOL discussions would be older, sicker, and have a worse prognosis, that was not the case. This may signify that clinicians are not routinely relying on signs of advanced HF to trigger these discussions. Furthermore, while prior work has suggested that disease specialists may be more accurate at prognostication in advanced illness(18), we found no difference in the proportion of patients reporting prior EOL conversations in those followed by our multidisciplinary HF clinic compared with other clinics.

Patients that did report prior EOL discussions with their physicians more often had an AD, were more familiar with hospice, and had attitudes about dying and hospice that more closely aligned with palliative care principles. While the cross-sectional nature of these data precludes any conclusions about causality, it is reasonable to consider that these discussions may have had an impact on the patient's completion of ACP documents and knowledge of EOL options.

There are some limitations to acknowledge. First, patient responses to questionnaire items were open to misinterpretation. Second, we asked patients to recall prior discussions with physicians, and the possibility of recall bias exists. Finally, this study reflects the perceptions of patients with HF living in a single community. The study population is predominantly 
Caucasian, which may limit the generalizability to populations of varying racial and ethnic diversity.

\section{Conclusion}

Despite increasing recognition of the importance of EOL discussions and ACP in patients with HF, patients perceive they are still occurring infrequently. This represents an important modifiable gap in the optimal longitudinal care of patients with HF. Efficacious interventions targeted at increasing the occurrence of EOL discussions in patients with HF are needed.

\section{Supplementary Material}

Refer to Web version on PubMed Central for supplementary material.

\section{Acknowledgments}

FUNDING SOURCES: This work was funded by the NIH (K23 HL 116643, PI Dunlay).

\section{ABBREVIATIONS}

$\begin{array}{ll}\text { ACP } & \text { advance care planning } \\ \text { AD } & \text { advance directive } \\ \text { ADHF } & \text { acute decompensated heart failure } \\ \text { BMI } & \text { body mass index } \\ \text { DNR } & \text { Do Not Resuscitate } \\ \text { EOL } & \text { end-of-life } \\ \text { HF } & \text { heart failure }\end{array}$

MAGGIC Meta-analysis Global Group in Chronic Heart Failure

NYHA New York Heart Association

\section{References}

1. Mozaffarian D, Benjamin EJ, et al. Writing Group M. Executive Summary: Heart Disease and Stroke Statistics--2016 Update: A Report From the American Heart Association. Circulation. 2016; 133:447-54. [PubMed: 26811276]

2. Lindenfeld J, Albert NM, Boehmer JP, et al. Executive Summary: HFSA 2010 Comprehensive Heart Failure Practice Guideline. Journal of Cardiac Failure. 2010; 16:475-539.

3. Yancy CW, Jessup M, et al. Writing Committee M. 2013 ACCF/AHA guideline for the management of heart failure: a report of the American College of Cardiology Foundation/American Heart Association Task Force on practice guidelines. Circulation. 2013; 128:e240-327. [PubMed: 23741058]

4. Butler J, Binney Z, Kalogeropoulos A, et al. Advance directives among hospitalized patients with heart failure. JACC Heart Fail. 2015; 3:112-21. [PubMed: 25543976]

5. Dunlay SM, Swetz KM, Mueller PS, Roger VL. Advance directives in community patients with heart failure. Circ Cardiovasc Qual Outcomes. 2012; 5:283-9. [PubMed: 22581852] 
6. Dunlay SM, Foxen JL, Cole T, et al. A survey of clinician attitudes and self-reported practices regarding end-of-life care in heart failure. Palliat Med. 2015; 29:260-7. [PubMed: 25488909]

7. Pocock SJ, Ariti CA, McMurray JJ, et al. Predicting survival in heart failure: a risk score based on 39372 patients from 30 studies. Eur Heart J. 2013; 34:1404-13. [PubMed: 23095984]

8. Krumholz HM, Phillips RS, Hamel MB, et al. Resuscitation preferences among patients with severe congestive heart failure: results from the SUPPORT project. Study to Understand Prognoses and Preferences for Outcomes and Risks of Treatments. Circulation. 1998; 98:648-55. [PubMed: 9715857]

9. Phillips RS, Wenger NS, Teno J, et al. Choices of seriously ill patients about cardiopulmonary resuscitation: correlates and outcomes. SUPPORT Investigators. Study to Understand Prognoses and Preferences for Outcomes and Risks of Treatments. Am J Med. 1996; 100:128-37. [PubMed: 8629646]

10. Chamberlain AM, Manemann SM, Dunlay SM, et al. Self-rated health predicts healthcare utilization in heart failure. J Am Heart Assoc. 2014; 3:e000931. [PubMed: 24870937]

11. Chew LD, Bradley KA, Boyko EJ. Brief questions to identify patients with inadequate health literacy. Fam Med. 2004; 36:588-94. [PubMed: 15343421]

12. Engelberg R, Downey L, Curtis JR. Psychometric characteristics of a quality of communication questionnaire assessing communication about end-of-life care. J Palliat Med. 2006; 9:1086-98. [PubMed: 17040146]

13. Hibbard JH, Mahoney ER, Stockard J, Tusler M. Development and testing of a short form of the patient activation measure. Health Serv Res. 2005; 40:1918-30. [PubMed: 16336556]

14. Manu E, Mack-Biggs TL, Vitale CA, Galecki A, Moore T, Montagnini M. Perceptions and attitudes about hospice and palliative care among community-dwelling older adults. Am J Hosp Palliat Care. 2013; 30:153-61. [PubMed: 22556283]

15. Peterson PN, Shetterly SM, Clarke CL, et al. Health literacy and outcomes among patients with heart failure. JAMA. 2011; 305:1695-701. [PubMed: 21521851]

16. Sartipy U, Dahlstrom U, Edner M, Lund LH. Predicting survival in heart failure: validation of the MAGGIC heart failure risk score in 51,043 patients from the Swedish heart failure registry. Eur J Heart Fail. 2014; 16:173-9. [PubMed: 24464911]

17. Allen LA, Stevenson LW, Grady KL, et al. Decision making in advanced heart failure: a scientific statement from the American Heart Association. Circulation. 2012; 125:1928-52. [PubMed: 22392529]

18. Warraich HJ, Allen LA, Mukamal KJ, Ship A, Kociol RD. Accuracy of physician prognosis in heart failure and lung cancer: Comparison between physician estimates and model predicted survival. Palliat Med. 2016; 30:684-9. [PubMed: 26769732] 


\section{HIGHLIGHTS}

- $\quad$ The vast majority of patients hospitalized with acute decompensated heart failure say they have never discussed their wishes for end-of-life care with their doctor.

- $\quad$ End-of-life discussions were no more common in patients with worse prognosis.

- $\quad$ Patients who recall having discussions were more knowledgeable about endof-life options and more likely to have completed an advance directive. 


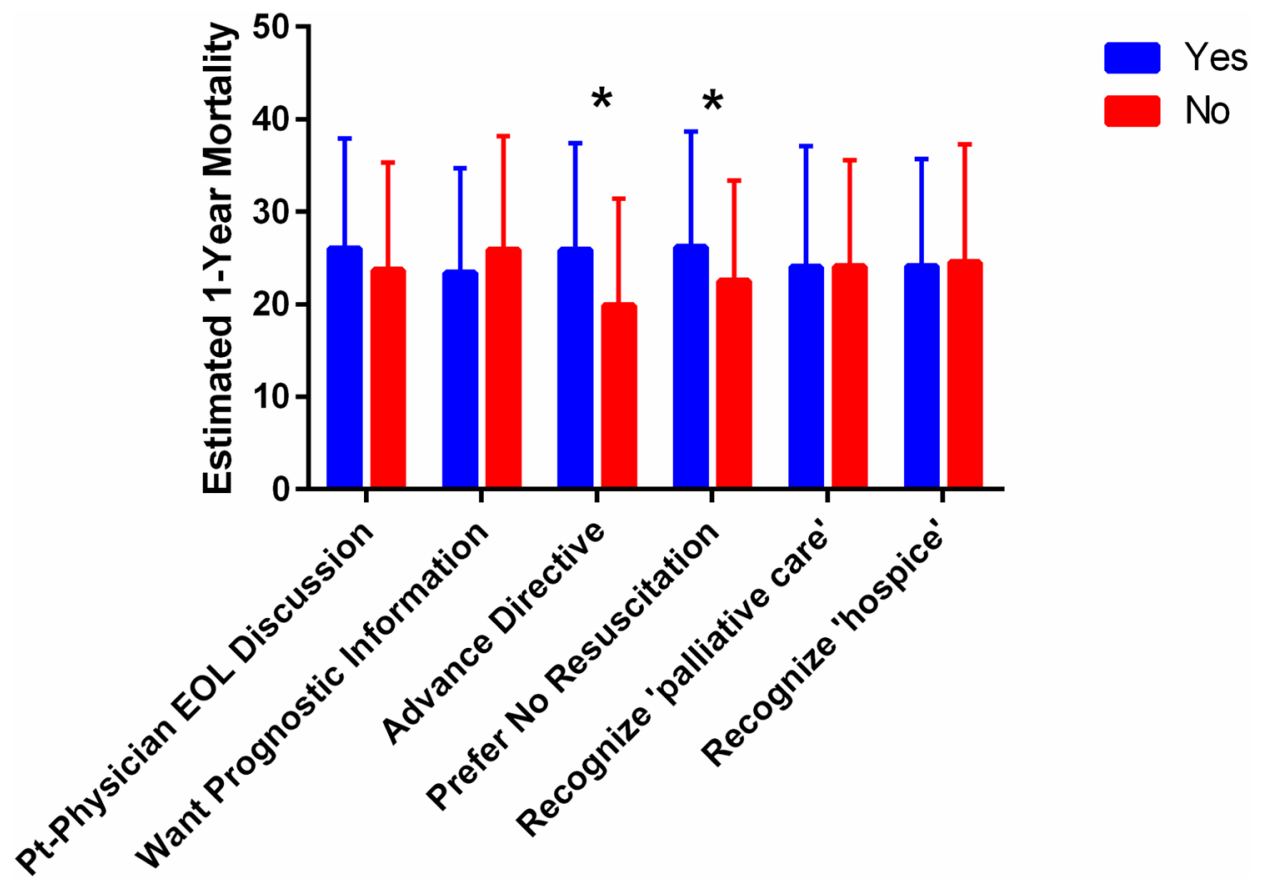

Figure. Advance Care Planning and End-of-Life Preferences According to Risk of Death The mean (standard deviation) estimated 1-year MAGGIC mortality for patients responding 'yes' or 'no' to each patient-reported variable are shown. Data were analyzed using 2 sample t-tests with MAGGIC estimated mortality as a continuous variable and patient-reported variable as a yes/ no binary variable. $\mathrm{P}$ values $<0.05$ are designed with a $*$. Exact $\mathrm{p}$ values are: patient-physician end-of-life discussion $\mathrm{p}=0.14$, patient indicates preference to receive prognostic information $\mathrm{p}=0.053$, patient has an advance directive $\mathrm{p}<0.001$, patient prefers no resuscitation $\mathrm{p}=0.002$, patient recognizes term 'palliative care' $\mathrm{p}=0.94$, and patient recognizes the term 'hospice' $\mathrm{p}=0.82$. 


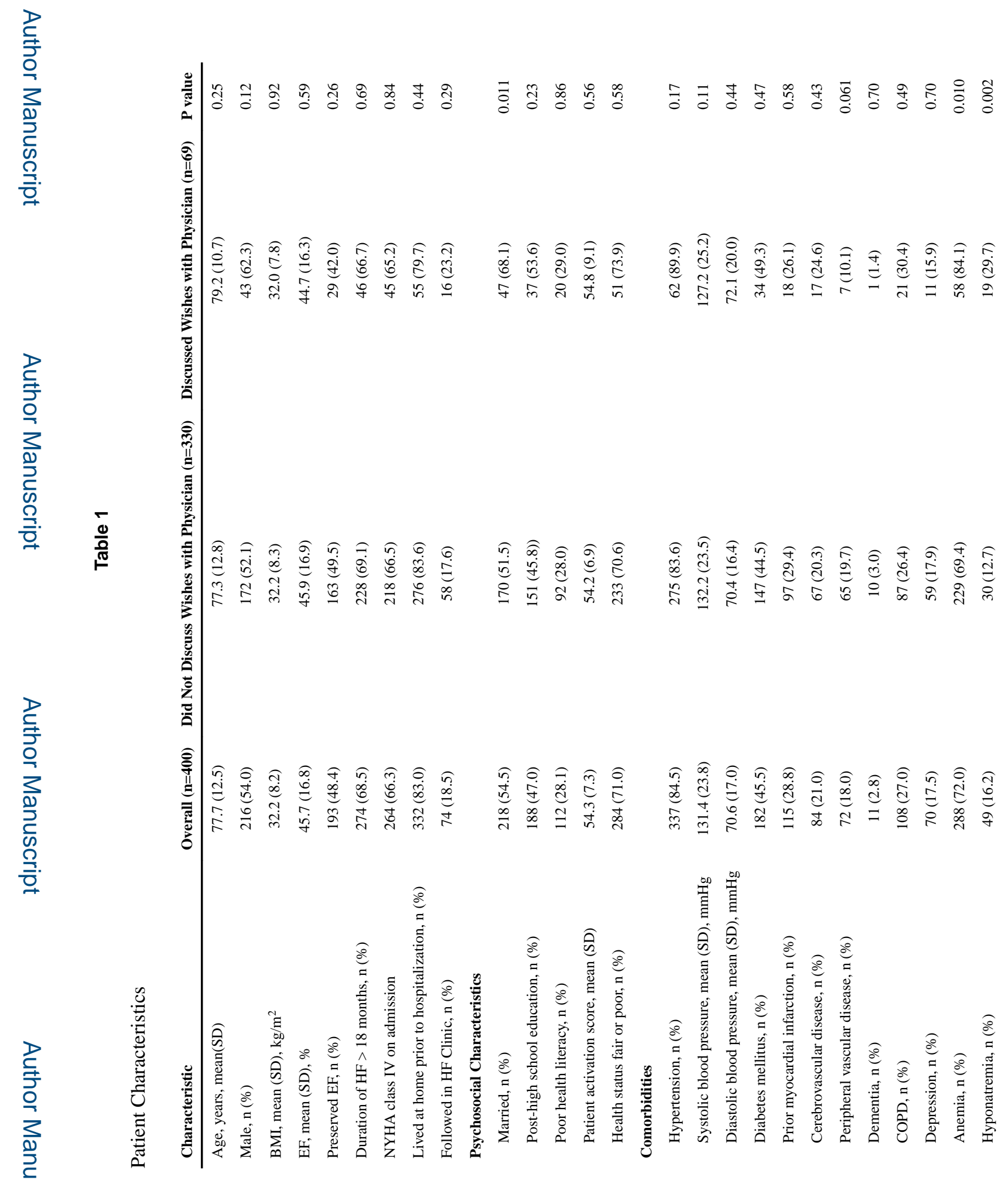




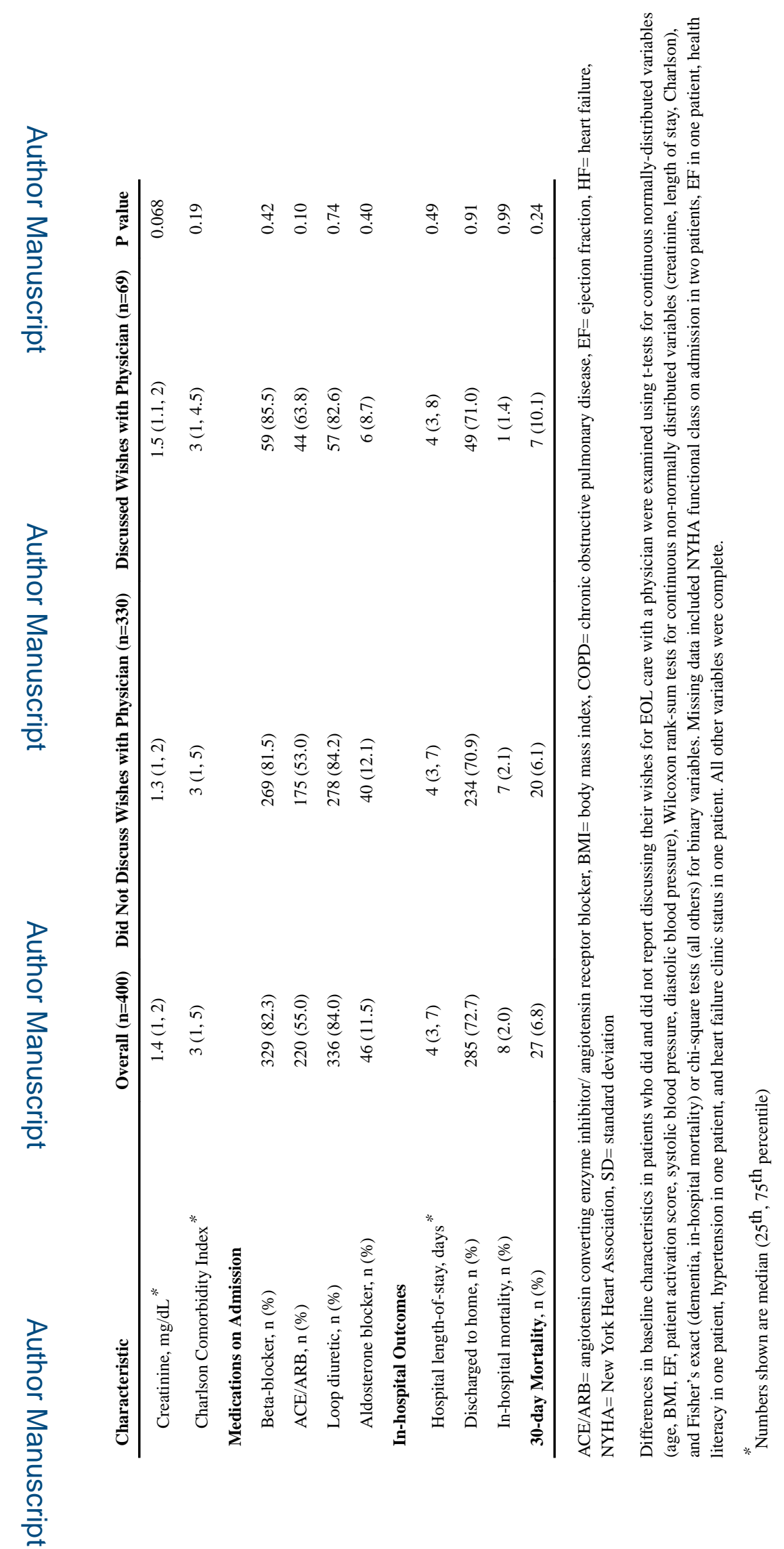

J Card Fail. Author manuscript; available in PMC 2018 November 01. 


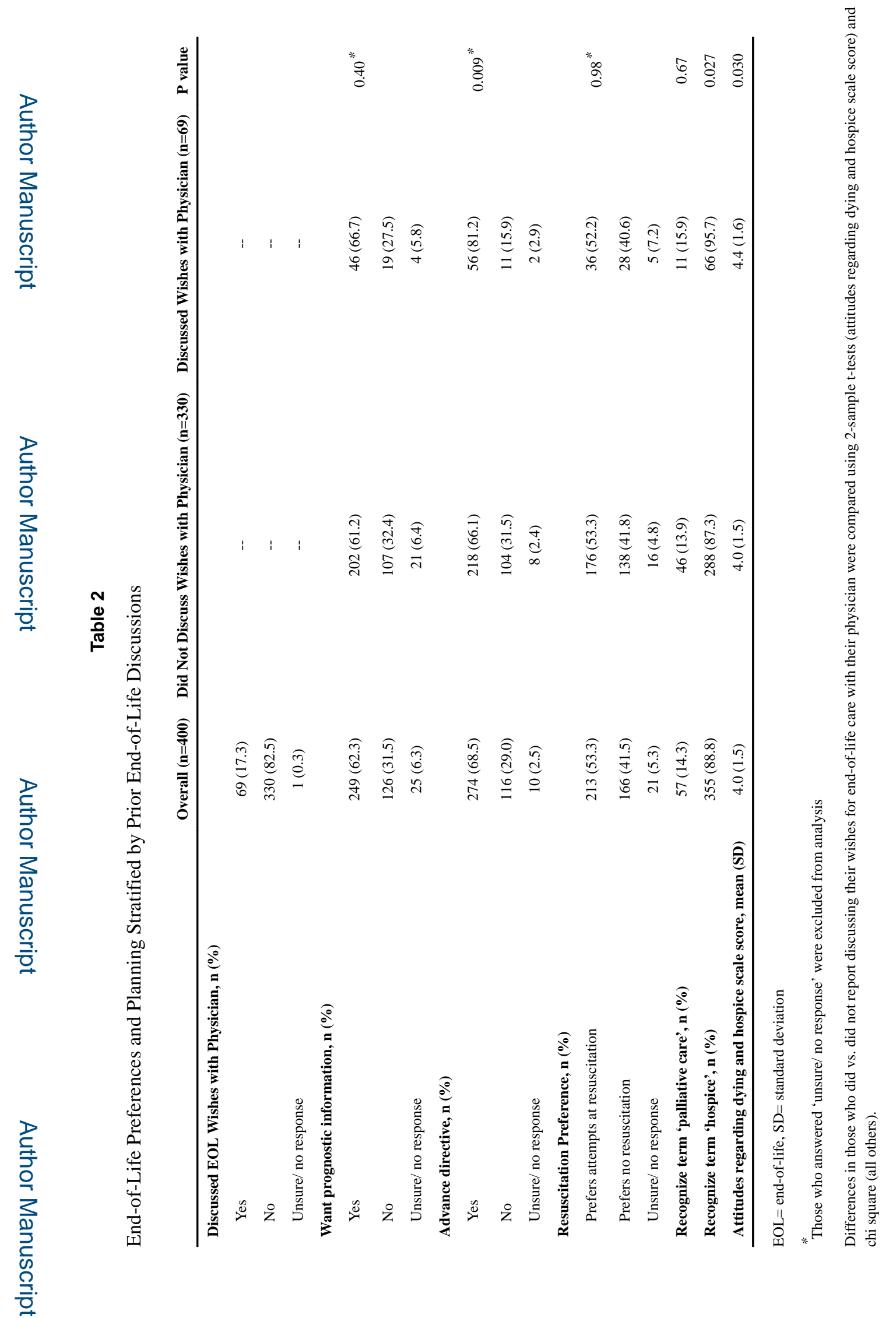

J Card Fail. Author manuscript; available in PMC 2018 November 01. 